\section{THE WABASH CENTER}

JOURNAL on TEACHING

\title{
The Negotiated Self: Employing Reflexive Inquiry to Explore Teacher Identity
}

\author{
Ellyn Lyle, editor \\ Leiden, the Netherlands: Brill, 2018 (xxiii + 235 pages, ISBN 978-90-04-38890-1, \\ \$39.00)
}

Reviewed By
Leslie Cara Fuller
Southern Methodist University

The Negotiated Self presents a series of nineteen reflections on teaching identity from different practitioners and educators of teachers. The result is a diffuse definition by example after example. By taking a step back from planning and executing, these teachers create space to consider their ongoing development and to emphasize the need for teaching with authenticity and presence.

Ellyn Lyle curates the essays that share experiences through creative expression, meditative practice, reflexive inquiry, and conversations with others about what it means to be a teacher. She writes, "A teaching life, while deeply meaningful, can also be marked by feelings of disconnection" (6). Lyle proposes reflexivity as a way to counteract such feelings. David Jardine's foreword begins the book in this same vein: just as the curriculum is a process, so too is the teacher. Instead of presenting an outline of the volume, he reflects on the common themes that result from the recognition of the fluidity of one's teaching identity in relation to students, subject, and practice.

The educational theories of Palmer, Freire, Pinar, Dewey, and others make frequent appearances, but this volume is primarily one of reflection, not theorizing. This is far from traditional academic writing with theses, evidence, and theories. Instead, it is something more meandering, but also more revelatory. The essays toward the beginning focus mostly on reflection through creating. Models show how photography, poetry, storytelling, handicrafts, gardening, and personal narratives can serve as vehicles for the reflective work.

The collection then shifts to more direct conversation with theorists. The most compelling of these is Lana Parker's engagement with Levinas, noting "Teaching is an ongoing process of facing the Other. As such, teacher identity is subject to the Other as it is repeatedly called into question" (128). The last chapters present the work of inviting others to reflect on their teaching through conversation. The contributors demonstrate that understanding oneself is not a straightforward task, so they write or craft or play their way through the reflection and hope to come up with a better sense of selfunderstanding on the other side.

"Identity is inevitably complex, multi-voiced, and always under construction" (50). In a time in which teaching, its methods, and the identity of the teacher have all been called into question, this volume provides many entries for faculty hoping to process and reassess their own roles and identities. It might be even more helpful for faculty developers brainstorming ideas for inviting faculty to reflect on their teaching identity. In the fields of theology and religious studies-which often result in a variety of fluid identities - these reflective approaches may be especially fruitful. Few of the contributors mention religion explicitly, but they do address the balance of multiple identities and how personal convictions influence one's teaching positionality. It is a collection that invites one's own reflection in response. 